\title{
The Role of Entrepreneurship in Changing The Employment Rate in The European Union
}

\section{Athanasios Anastasiou ( $\nabla$ athanastas@uop.gr)}

University of Peloponnese - Tripoli Campus: Panepistemio Peloponnesou https://orcid.org/0000-00034546-7846

\section{Vasiliki Argiri}

University of Peloponnese - Tripoli Campus: Panepistemio Peloponnesou

\section{Dimitrios Komninos}

University of Peloponnese - Tripoli Campus: Panepistemio Peloponnesou

\section{Zacharias Dermatis}

University of Peloponnese - Tripoli Campus: Panepistemio Peloponnesou

\section{Christos Papageorgiou}

University of Peloponnese - Tripoli Campus: Panepistemio Peloponnesou

\section{Research}

Keywords: Entrepreneurship, Entrepreneurship Indicators, Unemployment, Economic Growth.

Posted Date: September 30th, 2021

DOI: https://doi.org/10.21203/rs.3.rs-889454/v1

License: (c) (i) This work is licensed under a Creative Commons Attribution 4.0 International License.

Read Full License 


\title{
The role of entrepreneurship in changing the employment rate in the European Union
}

Athanasios Anastasiou1, Vasiliki Argiri², Dimitrios Komninos ${ }^{3}$, Zacharias Dermatis ${ }^{4}$, Christos Papageorgiou ${ }^{5}$

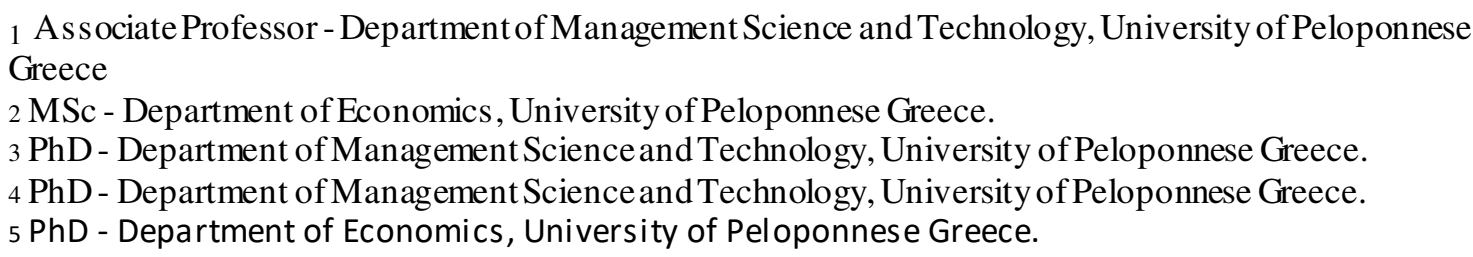

\begin{abstract}
The aim of this research is to examine the concept of entrepreneurship in the context of modern economic realities by presenting features and factors that contribute to economic growth. High unemployment, low economic growth and shrinking investment are key features of the long-term economic crisis at both national and European level.

New entrepreneurship, combined with the strengthening of the existing one, is a powerful antidote to the fight against unemployment, as it provides the opportunity, mainly to young people, to innovate and create new products and services contributing to the wider economic and social whole, reducing unemployment while creating the right conditions for a remarkable and outward-looking economy. Taking into account the literature research, it is examined how the development of entrepreneurship actually contributes to the encouragement of economic activity, creating a favorable ground for growth in all sectors of the economy and the creation of new jobs.
\end{abstract}

Keywords: Entrepreneurship, Entrepreneurship Indicators, Unemployment, Economic Growth. 


\section{Introduction}

The economic crisis that has hit our country in recent years, as a result of the international economic crisis that took place in 2006, starting from the USA, has resulted in an increase in unemployment, a decrease in the standard of living of Greek households, a decline in their incomes, a reduction in investment and the closure of a number of small and medium-sized enterprises.

Within the European Union, the issue of entrepreneurship is given special attention, as incentives are given and new professional initiatives are supported with a view to making the economy more dynamic and competitive. The Lisbon Council of April 2000 set out, on the one hand, the priorities for strengthening entrepreneurship and the strategies for encouraging entrepreneurial initiatives to invest mainly in the economy, knowledge and innovation, and, on the other hand, the emphasis was placed on improving the business environment. In our country, as a member of the European Union, it is possible to integrate the EU's objectives into the its national development policy, to take advantage of the incentives and opportunities provided, such as obtaining support from european bodies, education and subsidies, and ultimately to develop a more favorable business environment. This research aims to explore the concept of entrepreneurship, examine the obstacles, incentives and factors that affect it, as well as try to analyze the contribution of the size of the business to the formation of the business. The link between encouraging entrepreneurial activity and improving economic aggregates, such as increasing employment, enhancing competitiveness and productivity, is underlined. Finally, the way in which entrepreneurship contributes to the recovery of the economy, to the creation of an attractive environment for investment and ultimately to economic growth is analyzed.

\section{Literature review}

The concept of entrepreneurship and the presence of the entrepreneur could be implicitly denoted by the concept of 'knowledge' defined in the Karlsson model (Karlsson, 2004). Generally speaking, entrepreneurship is not consistent with the principles on which neoclassical theory is based. According to Wenneker and Thurik (1999) it is for two reasons: The first relates to the axiom of Perfect Competition, which is a prerequisite of neoclassical theory and which presupposes that there are no opportunities for profit and therefore 
entrepreneurs are not willing to take new business actions and cultivate opportunities. The second reason relates to the fact that the neoclassical model of economic growth is a model of general equilibrium, which implies that it does not take into account the concept of entrepreneurship. Critics of the neoclassical paradigm see imbalance conditions as the market and entrepreneurship as a balancing process. On the other hand, the axioms of endogenous development theory leave room for entrepreneurial activity. According to Romer (1986) the driving force for economic growth is research through which the design of the production process takes place. Also, Schultz argues that both the number and quality of entrepreneurial initiatives can be enhanced by investing in entrepreneurial capabilities. It is worth noting here that in both neoclassical theory and endogenous development theory, technology is mentioned in particular. According to North and Thomas (1973), innovation factors, economies of scale, education, capital accumulation and, do not constitute growth factors but constitute growth itself. One of the pivotal roles of entrepreneurship education has been the empowerment of its participants towards business venturing. Through knowledge delivery and cultivation of entrepreneurial skills, entrepreneurship education aims to make entrepreneurship more inclusive and with social and economic impact (Kakouris et.al, 2018).

Wenneker and Thurik (1999) point out that legal incentives and competition rules are determinants of the growth of businesses and the impact of entrepreneurship on economic growth. Finally, it is considered appropriate to refer to the view of Grebel (2000), in which each has an entrepreneurial spirit, human capital and venture risk capital. Different routines are tested within the market and the most suitable entrepreneurs survive and call in through the natural selection process.

We should not forget the mechanisms of entrepreneurship as an instrument of economic development.

\footnotetext{
According to Hebert and Thurik (1989) the role of the 'new entry' and the role of the 'new' are the most important roles in entrepreneurship in terms of its connection with economic development. The role of 'new entry' is to do with the entrepreneur who creates, operates and organizes a new business whether or not they are implementing some innovation. It is
} 
he who creates new jobs and contributes to the development of competition by considering it a link between entrepreneurship and economic growth. On the other hand the role of the 'new' refers to the entrepreneur who innovates and transforms knowledge, ideas and inventions into economically viable entities. And this second role emphasizes the link between entrepreneurship and economic growth. The implementation of innovative solutions requires and implies the desire to remove existing technologies and practices and introduce new innovations. Innovation can be applied to the product market through new product design, advertising, promotion and market research, but also in the form of technological innovation through product and process development, industry knowledge, research and emphasis on know-how. The diagram below shows the Wennekers mechanism. and Thurik (1999) through which the micro-economic operator is linked to economic growth at the macroeconomic level (Zervoyianni et al., 2014; Zervoyianni \& Anastasiou, 2009). According to Acs (1992) it is small business units that play an important role in the development of an economy as they contribute to the creation of innovative activities, evolve the industry and create new jobs. Baumol (1993) was also involved in the role of business actions and their potential impact. A number of surveys followed up on the positive relationship between entrepreneurship and economic growth.

Also Hayton, George and Zahra (2002) created a model that suggests a close link between entrepreneurship and culture - the culture of an economy. It includes at an individual level the person's cognitive background, the motivations and needs he wishes to satisfy as well as his cultural values. It should be stressed here that recent econometric surveys stress that entrepreneurship is a key factor in economic growth. According to Audretsch and Thurik (2004) the positive impact of entrepreneurship on economic growth has already been verified through a wide range of observation units including establishment, business, industry, the region and the country and show that a lack of entrepreneurship leads to a decline in economic growth.

Finally, the shift in the administrative economy towards a business economy (Audretsch and Thurik, 2004) has a number of implications. The most important is the growing role of small business entrepreneurship as a driver for economic growth (Lyroni et.al, 2018; Anastasiou et al. (2021); Anastasiou \& Panagiotopoulou (2020)). 
Looking at the link between entrepreneurship and economic growth, the majority of surveys focus on the impact of entrepreneurship on employment and consequently on reducing unemployment. Dujowich (2012) analyzed the impact of three forms of entrepreneurship, self-employment, new businesses and indicators developed by the Global Entrepreneurship Monitor and World Entrepreneurship bank Group Entrepreneurship Survey, in economic development.

As far as self-employment is concerned, the results of surveys preceding that of PlehnDujowich, mentioned by the latter, are mixed. Some surveys have shown that selfemployment has a positive impact on total employment, while others show that the annual change in the employment rate has a negative impact on GDP.

It is worth noting that this effect depends on the period in which the relationship is being considered, because it is necessary to arrive at a certain time in order to be perceived. However, the majority of surveys show that there has been a positive impact on employment since the creation of new enterprises, especially during their early years. However, this positive effect may weaken over the years, as there are studies supporting the positive effect of new businesses on employment in the short term or even in the long term but not in the medium term. The factors determining whether the creation of a new business will have a positive or negative impact on employment include, inter alia, the form of market entry, the sector and the specific characteristics of the region in which it operates and the period of its creation.

The Global Entrepreneurship Monitor (GEM) has designed a series of indicators to assess business activity in different countries, and measure Total Entrepreneurship Activity (TDI) and Incubating Entrepreneurship (TVA). The results of GEM's research show that the link between entrepreneurship and economic growth. We note that a survey shows that the relationship between nascent entrepreneurship and the level of economic development as measured by per capita income or the innovation index is $\mathrm{U}$-shaped. This is not a problem. Another study addressed the impact of the four forms of entrepreneurship (ISF, opportunistic ISF, forced ISF and high growth potential ISF) on GDP growth per employee and showed that there is a positive correlation. Finally, it has also been shown that the impact of the ISF on economic growth and employment depends on the level of per capita income, in particular 
there is a negative relationship in the case of poor countries and a positive one in the case of rich countries.

Another survey tries to compare data collected by GEM on early stage entrepreneurship with World Bank Group Entrepreneurship Survey which record formal business records. More specifically, it compared the GEM data on new entrepreneurship to a percentage of the adult population of 18-64 years and entrepreneurship in WBGES as a number of newly registered businesses in percentage of the adult population and found the difference between them. The result of the survey is summarized in that the entry of new businesses into WBGES is higher than in GEM in developed countries, while WBGES has lower levels of first-stage entrepreneurship in developing countries compared to GEM. The survey found that these differences were due to local institutional barriers such as difficulty in starting up, difficulty in running, difficulty in dissolving a business, and operational risks such as financial, political and law of order.

Business development is a factor that influences economic growth in many, different ways. New businesses reduce unemployment, but that is not always the case. It is the entrepreneur who usually plays a special role in the initial development of industries, due to the introduction of new products and processes, but in the long term productivity is enhanced through competition. New entrants offer insight into what consumers prefer as they introduce variations of existing goods and services into the market. This knowledge, however, is not confined to the new entrant but is shared by all companies in the sector and plays an important role in the production process. Another important element is the fact that selfemployed people tend to work longer hours than employees

as a result, they are more productive because their income is linked to their effort and their working time.

\section{Econometric Model Methodology}

\section{Presentation of Data of the Econometric Model}

The purpose of this paper is to examine whether entrepreneurship contributes to the change in the employment rate in the European Union, i.e. how the number of enterprises 
of different sizes affects the employment rate in each EU country. Below we will provide a detailed description of the dependent and independent variables used in our example:

- $\quad$ EPM (employment): It refers to the size of employment as a percentage of the total population of each country, for the active population aged 15-64. It can express the link between entrepreneurship and economic development for each country of the European Union.

- NBD: This indicator is called New entry Business Density and is intended to measure business activity. Defined as the number of new entrants per 1,000 people aged 15-64. Identifies current trends in the creation of new businesses in a region, the relationship between entrepreneurship,

the financial crisis has affected business activity. We introduce the variable "NBD" to represent the natural algorithm of new-business entry density.

- $\quad$ EMP1: This ratio relates to the number of employees employed by a business. Businesses can be classified into different categories according to their number of employees. In small and medium size less than 250 people are employed. We introduce the variable "EMP1" which represents the natural algorithm for small businesses with 19 employees.

- $\quad$ EMP2: This ratio relates to the number of employees that a business employs. This case,too, identifies small companies and we are considering whether they contribute to increased employment and thus economic growth. We introduce the variable "EMP2" which represents the natural algorithm for small businesses employing 10-19 employees. - $\quad$ EMP3: And this ratio refers to the number of employees that a business employs. Identifies small businesses and is a means of measuring the business that takes place in a specific location, at a specific time period. We introduce the variable "EMP3" which represents the natural algorithm for small businesses employing 20-49 employees.

- EMP4: It is the ratio that expresses the number of employees employed by a business. In this case we are referring to medium-sized enterprises, so we introduce the variable "EMP4" which 
represents the physical algorithm for medium-sized businesses employing 50-249 workers.

- EMP5: It is the ratio that expresses the number of employees employed by a business. We are talking here about large-scale enterprises. We introduce the variable "EMP5" which represents the natural algorithm for large businesses with more than 250 employees.

- DCRISIS: defined as the dummy judgment variable. It is set to 0 for 2005-2008 and 1 for 2009-2015.

The econometric study we present refers to the period from 2005 to 2016 . The data collection was made from the following three sites: https://ec.europa.eu/eurostat, http://www.oecd.org and http://www.doingbusiness.org and concern the 26 of the 28 countries of the European Union. In our study, we did not include Lithuania and Luxembourg because of a lack of data, so our model looks like this:

$\mathrm{Y}_{\mathrm{it}=} \mathrm{b}_{0+} \mathrm{b}_{1} \mathrm{x}_{1 \mathrm{it}}+\mathrm{b}_{2} \mathrm{X}_{2 \mathrm{it}}+\ldots+\mathrm{b}_{7} \mathrm{X}_{7 \mathrm{i}} \mathrm{t}+\mathrm{U}_{\mathrm{it}}$ where,

- $\quad \mathrm{Y}_{\mathrm{it}}$ is the natural algorithm of employment size in country $\mathrm{i}$ for the year $\mathrm{t}$,

- $\quad \mathrm{X}_{1 \mathrm{it}}$ is the entry density of new businesses into business in country $\mathrm{i}$ for year $\mathrm{t}$ (NBD),

- $\quad \mathrm{X}_{2 \mathrm{it}}$ is the natural algorithm for enterprises employing 1-9 workers in country $\mathrm{i}$ for year t (EMP1),

- $\mathrm{X}_{3 \mathrm{it}}$ is the natural algorithm for enterprises employing 10-19 workers in country $\mathrm{i}$ for year t (EMP2),

- $\mathrm{X}_{4 \mathrm{it}}$ is the natural algorithm for enterprises employing 20-49 workers in country $\mathrm{i}$ for year $\mathrm{t}(\mathrm{EMP} 3)$,

- $\mathrm{X}_{5 \mathrm{it}}$ is the natural algorithm for enterprises employing 50-249 workers in country $\mathrm{i}$ for the year $\mathrm{t}(\mathrm{EMP} 4)$,

- $\mathrm{X}_{6 \mathrm{it}}$ is the natural algorithm for enterprises employing more than 250 workers in country i for the year $t$ (EMP5),

- $\quad \mathrm{X}_{7 \mathrm{it}}$ is the pseudo-variable of judgment and

- $\quad \mathrm{U}_{\mathrm{it}}=\mathrm{m}_{\mathrm{t}}+\mathrm{e}_{\mathrm{i}}+\mathrm{c}_{\mathrm{i}}$, 
with $\mathrm{m}_{\mathrm{t}}$ being defined as the constant term that changes over time to take into account the constant longitudinal effects, i.e. those factors that influence the dependent variable and change over time but not over time;

with $e_{i}$ being a random term that is varied across layers in order to take into account random stratified effects, i.e. those factors that affect the dependent variable and change over time but not over time;

with $\mathrm{c}_{\mathrm{i}}$ being the non-observed variable that does not change over time for $\mathrm{i}=1,2, \ldots, \mathrm{N}$.

\subsection{Data Description}

The following table captures a series of the most important descriptive statistics for each variable separately included in the empirical analysis, such as mean, median, maximum, minimum, standard deviation (std.dev.), and others.

\begin{tabular}{|c|l|l|l|l|l|l|}
\hline \multicolumn{6}{|c|}{ Descriptive Statistics of the Independent Variables of the Model } \\
\hline & NBD & EMP1 & EMP2 & EMP3 & EMP4 & EMP5 \\
\hline & 2.953735 & 18.27705 & 1.991825 & 1.711633 & 2.814587 & 0.994803 \\
\hline Median & 2.4570 & $-0,07480$ & $-1,22305$ & $-0,51835$ & $-0,4585$ & $-0,500$ \\
\hline Maximum & 79.9942 & 2506.402 & 242.9553 & 288.3228 & 700,000 & 210.2804 \\
\hline Minimum & $-100,000$ & $-60,72390$ & $-56,7164$ & $-44,2623$ & $-87,2727$ & $-64,354$ \\
\hline Std. Dev & 17.98026 & 182.54360 & 23.94632 & 22.93305 & 75.06367 & 21.53469 \\
\hline Skewness & 0.082987 & 11.81438 & 5.656449 & 3.421353 & 3.80336 & 5.441925 \\
\hline Kurtosis & 9.582329 & 149.04530 & 49.32716 & 76.93088 & 12.6391 & 58.09383 \\
\hline Jarue - Bera & 457.0298 & 245322.9 & 25584.61 & $03,209.1$ & 506721.2 & 35081.17 \\
\hline Probability & 0.00000 & 0.00000 & 0.00000 & 0.00000 & 0.00000 & 0.00000 \\
\hline & 747.295 & 4916.526 & 537.7927 & 765.5724 & 65.5676 & 261.6333 \\
\hline Sum Sq. Dev & 81469.01 & 8930337 & 154251.6 & 42525.7 & 550329.0 & 121500.7 \\
\hline Observation & 53 Details & 69 Details & 70 Details & 72 Details & 72 Details & 63 Details \\
\hline
\end{tabular}

Table 1: Descriptive statistics of the independent variables of the model

Before proceeding with the regression process, however, the necessary Correlation test of independent $\mathrm{X}$ variables should be preceded. The table below shows the degree of correlation among the variables in the template we are studying.

\begin{tabular}{|c|c|c|c|c|c|}
\hline \multicolumn{6}{|c|}{ Correlation of Dependent Variables } \\
\hline NBD & EMP1 & EMP2 & EMP3 & EMP4 & EMP5 \\
\hline
\end{tabular}




\begin{tabular}{|l|l|c|c|c|c|c|} 
NBD & 1 & $-0,042246$ & 0,032963 & 0.004149 & 0.019759 & 0.045195 \\
\hline EMP1 & & 1 & 0.660549 & 0.338201 & 0.522494 & 0.164246 \\
\hline EMP2 & & & 1 & 0.436648 & 0.646797 & 0.297788 \\
\hline EMP3 & & & & 1 & 0.600965 & 0.769890 \\
\hline EMP4 & & & & & 1 & 0.632841 \\
\hline EMP5 & & & & & & 1 \\
\hline
\end{tabular}

Table 2: Correlation of Dependent Variables

The matrix shows that in the majority of combinations there is a positive linear correlation while the degree of dependency between the variables, in most pairs, is small proving that there is no high linear correlation.

\section{The Empirical Tests and their Results}

In the context of this work, eight (8) Regressions were performed using the Least Squares Method.

Using the econometric program E-Views 9 we performed all the regressions, with Dependent variable the size of employment as a percentage of the total population (EMP) and independent variables the density of entry of new businesses in business (NBD), the number of businesses employing 1-9 workers (NBD) EMP1), the number of enterprises employing 10-19 workers (EMP2), the number of enterprises employing 20-49 workers (EMP3), the number of enterprises employing 50-249 workers (EMP4), the number of enterprises employing over 250 workers (EMP5) as well as the Pseudo-Crisis Variable (DCRISIS).Our econometric study refers to the period from 2005 to 2016, the data collection was made from the following three sites: https://ec.europa.eu/eurostat, http://www.oecd.org and http://www.doingbusiness.org and concern the 26 of the 28 countries of the European Union. In our study we did not include Lithuania and Luxembourg because of a lack of data.

First we estimate our model by the Least Squares Method (OLS), ignoring the dimensions of time and space and then performing the regressions according to the Models. In order to select the most appropriate model we conduct the Hausman Test.

The following table shows the results of the Regressions of our Template: 


\begin{tabular}{|c|c|c|c|c|c|c|c|c|}
\hline \multicolumn{9}{|c|}{ Master Regression Results } \\
\hline & \multicolumn{8}{|c|}{ Dependent Variable: Employment as percentage of total population (EMP) } \\
\hline $\begin{array}{l}\text { Independent } \\
\text { Variables }\end{array}$ & EQ1 & EQ2 & EQ3 & EQ4 & EQ5 & EQ6 & EQ7 & EQ8 \\
\hline Constant & $\begin{array}{c}0.233430 \\
(0.1144) \\
\end{array}$ & $\begin{array}{c}0.311926 \\
(0.0357) \\
\end{array}$ & $\begin{array}{r}0.156819 \\
(0.2966) \\
\end{array}$ & $\begin{array}{c}0.405794 \\
(0.0055) \\
\end{array}$ & $\begin{array}{c}0.319870 \\
(0.0293)\end{array}$ & $\begin{array}{c}0.198704 \\
(0.1871)\end{array}$ & $\begin{array}{c}0.088330 \\
(0.5616)\end{array}$ & $\begin{array}{c}0.192835 \\
(0.1892)\end{array}$ \\
\hline NBD & $\begin{array}{c}0.022182^{* *} \\
(0.0096)\end{array}$ & & $\begin{array}{c}0.021731^{* *} \\
(0.0118)\end{array}$ & & & $\begin{array}{c}0.019286^{* *} \\
(0.0246)\end{array}$ & $\begin{array}{c}0.019895^{* *} \\
(0.0216)\end{array}$ & $\begin{array}{c}0.020714^{* *} \\
(0.0135)\end{array}$ \\
\hline EMP1 & & & & $\begin{array}{c}-0,002142^{* *} \\
(0.0143)\end{array}$ & $\begin{array}{c}-0,003075^{* *} \\
(0.0011)\end{array}$ & $\begin{array}{c}-0,001931^{* *} \\
(0.0232)\end{array}$ & & $\begin{array}{c}-0,003606^{* *} \\
(0.0002)\end{array}$ \\
\hline EMP2 & & & $\begin{array}{c}0.020209^{* *} \\
(0.0218)\end{array}$ & & $\begin{array}{c}0.026798^{* * *} \\
(0.0005)\end{array}$ & & $\begin{array}{c}0.023433^{* *} \\
(0.0264)\end{array}$ & $\begin{array}{c}0.036008^{* * *} \\
(0.0007)\end{array}$ \\
\hline EMP3 & & & & $\begin{array}{c}0.020704^{* * *} \\
(0.0036)\end{array}$ & & $\begin{array}{c}0.018360 * * * \\
(0.0083)\end{array}$ & & $\begin{array}{c}0.013764^{* *} \\
(0.0456)\end{array}$ \\
\hline EMP4 & & & & & & & & \\
\hline EMP5 & & $\begin{array}{c}0.018359 * * \\
(0.0112) \\
\end{array}$ & & & $\begin{array}{c}0.018480^{* *} \\
(0.0102) \\
\end{array}$ & & $\begin{array}{c}0.013101^{*} \\
(0.0808)\end{array}$ & \\
\hline Observations & 253 Details & 263 Details & 241 Details & 269 Details & 260 Details & 240 Details & 233 Details & 240 Details \\
\hline R-squared & 0.137966 & 0.128904 & 0.178268 & 0.161969 & 0.185671 & 0.193734 & 0.176376 & 0.237179 \\
\hline \multicolumn{9}{|c|}{$\begin{array}{l}\text { Note: OLS estimation, } * * *, * *, * \text { indicate significance at } 1 \%, 5 \% \text { and } 10 \% \text { level respectively. } \\
\text { (White - heteroscedasticity - robust standard errors in parenthesis) }\end{array}$} \\
\hline
\end{tabular}

Table 3: Master Regression Results 


\section{Equation 1:}

In the first regression the dependent variable is the size of the employment as a percentage of the total population (EMP) and the independent variable is the natural algorithm of the entry density of new businesses in business activity (NBD). After the Hausman test, it was chosen as the most appropriate model of the Fixed Effects (Fixed Effects Model).

The result of the Regression is in line with economic theory as the factor of the entry density of new businesses in business activity presents a positive sign, which is fully confirmed by our literature review.Also the p-value of the independent variable indicates that this is statistically significant because $\mathrm{p}$-value $=0.0096$ which is less than 0.001 (statistical significance level of 99\%). Therefore, the regression function of the model resulting from the Fixed Effects Model (Fixed Effects Model) is as follows: $\mathrm{EMP}=0.233430+0.022182 \mathrm{NBD}+\mathrm{U}_{\mathrm{it}}$

\section{Equation 2:}

In the second regression the dependent variable is the amount of employment as a percentage of the total population (EMP) and the independent variable is the natural algorithm of the number of enterprises employing over 250 workers (EMP5). After the Hausman test, it was chosen as the most appropriate model of the Fixed Effects (EMP) (Fixed Effects Model).

The result of the Regression is consistent with economic theory as the factor of the number of enterprises employing more than 250 workers is positive, which shows that businesses employing more than 250 workers contribute positively to the increase in employment. Also the p-value of the independent variable shows that it is statistically significant because p--value value $=0.0112$ which is less than 0.05 (statistical significance level 95\%). Therefore, the regression function of the model resulting from the Fixed Effects Model (Fixed Effects Model) is as follows: $\mathrm{EMP}=0,311926+0,018359 \mathrm{EPM} 5+\mathrm{U}_{\mathrm{it}}$

\section{Equation 3:}

In the third regression the dependent variable is the amount of employment as a percentage of the total population (EMP) and the independent variables are the natural algorithm of the entry density of new enterprises in business activity (NBD) and the natural algorithm of the number of enterprises employing 10-19 workers (EMP2). Hausman, Fixed Effects Model was chosen as the most appropriate model. 
The result of this regression is consistent with economic theory, as both the factor of the entry density of new businesses into business and the factor of enterprises employing 10-19 employees present a positive sign, thus demonstrating their positive contribution to employment growth. Also the p-value of independent variables shows that these are statistically significant because for the first variable we have $p$-value $=0.0118$ which is less than 0.05 (statistical significance level 95\%) and for the second variable we have $\mathrm{p}$-value $=0.0218$ which is less than 0.05 (statistical significance level 95\%). Hence the regression function of the model derived from the Fixed Effects Method (Fixed Effects Model) is as follows: EMP=0,156819+ $0,021731 \mathrm{NBD}+0,020209 \mathrm{EMP} 2+\mathrm{U}_{\mathrm{it}}$

\section{Equation 4:}

In the fourth regression we study the dependent variable is the amount of employment as a percentage of the total population (EMP) and the independent variables are the natural algorithm of the number of enterprises employing 1-9 employees (EMP1) and the natural algorithm of the number of enterprises employing 20-49 employees (EMP3 After the Hausman check, the Fixed Effects Model was chosen as the most appropriate model (Fixed Effects Model).

According to the result of this regression, the factor of the number of enterprises employing 19 employees is negative while the factor of the number of enterprises employing 20-49 employees is positive. This underlines the fact that businesses with 1-9 employees do not contribute positively to the reduction of unemployment, while the contribution of businesses with 20-49 employees to the increase in employment is positive. The fact that the increase in employment did not automatically lead to a corresponding reduction in unemployment leads us to study the size of the labor force. There may be an increase in employment accompanied by a simultaneous influx of people into the labor force, so there may even be an increase in unemployment if there is a greater influx of people into the labor force than can be absorbed. Also the $\mathrm{p}$-value of independent variables shows that these are statistically significant because for the first variable we have $\mathrm{p}$--value $=0.0143$ which is less than 0.05 (statistical significance level of 95\%) and for the second variable we have $\mathrm{p}$-value $=0.0036$ which is less than 0.01 (statistical significance level of 99\%). Therefore the regression function of the model resulting 
from the Fixed Effects (Fixed Effects Model) is formed as follows: EMP=0,405794 0,002142EMP1 + 0,020704EMP3 $+\mathrm{U}_{\text {it }}$

\section{Equation 5:}

In the fifth regression performed by the dependent variable is the amount of employment as a percentage of the total population (EMP) and the independent variables are the natural algorithm of the number of enterprises employing 1-9 workers (EMP1), the natural algorithm of the number of enterprises employing 10-19 workers (EMP2) and the physical algorithm the number of enterprises employing more than 250 employees (EMP5). Following the Hausman Test, this model of Fixed Effects (Fixed Effects Model) was chosen as the most appropriate model.

According to the result of this regression, the factor of the number of enterprises employing 19 workers is negative while the factor of the number of enterprises employing 10-19 workers and the factor of the number of enterprises employing more than 250 workers is positive. This underlines the fact that businesses with 1-9 employees do not contribute positively to the reduction of unemployment, while the contribution of businesses with 10-19 and over 250 employees to the increase of employment is positive. The fact that the increase in employment did not automatically lead to a corresponding reduction in unemployment can be explained by the two-way relationship between entrepreneurship and unemployment. The increase in the number of new enterprises employing few workers is creating more competition, which leads to a decrease in the creation of new enterprises. It can also lead to the closure of the less competitive enterprises and we are heading towards an increase in unemployment. Also the pvalue of independent variables shows that these are statistically significant, because for the first variable we have $\mathrm{p}$-value $=0.0011$ of 0.01 (statistical significance level $99 \%$ ), for the second variable we have $\mathrm{p}$-value $=0.0005$ which is less than 0.01 (statistical significance level 99\%) and for the third we have p-value $=0.0102$ which is less than 0.05 (statistical significance level $95 \%$ ). Therefore, the regression function of the model resulting from the Fixed Effects Model (Fixed Effects Model) is as follows:

$\mathrm{EMP}=0.319870-0.003075 \mathrm{EMP} 1+0.026798 \mathrm{EMP} 2+0.018480 \mathrm{EMP} 5+\mathrm{U}_{\mathrm{it}}$ 


\section{Equation 6:}

In the sixth regression performed by the dependent variable is the size of the employment as a percentage of the total population (EMP) and the independent variables are the natural algorithm of the entry density of new enterprises in business activity (NBD), the natural algorithm of the number of enterprises employing 1-9 workers (EMP1) and the natural algorithm of the number of enterprises employing 2 0-49 employees (EMP3). After the Hausman Test, the Fixed Effects model (Fixed Effects Model) was chosen as the most appropriate model.

According to the result of this Regression, the factor of the number of enterprises employing 19 workers shows a negative sign, while the factor of the natural algorithm of the entry density of new enterprises in business (NBD) as well as the factor of the number of enterprises employing 20-49 workers shows a positive sign. Also the p-value of independent variables shows that these are statistically significant because for the first variable we have pvalue $=0.0246$ which is less than 0.05 (statistical significance level 95\%), for the second variable we have p-value $=0.0232$ which is less than 0.05 (statistical significance level $95 \%$ ) and for the third we have $p$ - value $=0.0083$ which is less than 0.01 (statistical significance level 99\%). Therefore, the regression function of the model resulting from the Fixed Effects Model is as follows: $\mathrm{EMP}=0,198704+0,019286 \mathrm{NBD}-0,001931 \mathrm{EMP} 1+0,018360 \mathrm{EMP} 3+\mathrm{U}_{\mathrm{it}}$

\section{Equation 7:}

In the seventh regression that we performed the dependent variable is the amount of employment as a percentage of the total population (EMP) and the independent variables are the natural algorithm of entry density of new enterprises in business (NBD), the natural algorithm of the number of enterprises employing 10-19 workers (EMP2) and the natural algorithm of the number of enterprises employ over 250 workers (EMP5). After the Hausman Test, the Fixed Effects model (Fixed Effects Model) was chosen as the most appropriate model. The result of this regression is in line with economic theory as the factor of the natural algorithm of entry density of new enterprises in business (NBD), the factor of the number of enterprises employing 10-19 workers as well as the factor of the number of enterprises employing over 250 
workers show a positive sign, demonstrating their positive contribution to employment growth. -value of independent variables indicates that these are statistically significant because for the first variable we have $\mathrm{p}$-value $=0.0216$ which is less than 0.05 (statistical significance level $95 \%$ ), for the second variable we have $\mathrm{p}$-value $=0.0264$ which is less than 0.05 (statistical significance level 99) 5\%) and for the third we have p-value $=0.0808$ which is less than 0.10 (statistical significance level of 90\%). Therefore, the regression function of the model resulting from the Fixed Effects Model is formed as follows:

$\mathrm{EMP}=0,088330+0,019895 \mathrm{NBD}+0,023433 \mathrm{EMP} 2+0,013101 \mathrm{EMP} 5+\mathrm{U}_{\text {it }}$

\section{Equation 8:}

In the eighth regression we performed the dependent variable is the amount of employment as a percentage of the total population (EMP) and the independent variables are the natural algorithm of entry density of new enterprises in business (NBD), the natural algorithm of the number of enterprises employing 1-9 workers (EMP1), the natural algorithm of the number of enterprises employing 1 0-19 employees (EMP2) and the natural algorithm of the number of enterprises with 20-49 employees (EMP3). Following the Hausman Test, the Fixed Effects (Model) was chosen as the most appropriate model.

The result of this Regression also agrees with economic theory as the factor of the natural algorithm of entry density of new enterprises in business activity (NBD), the factor of the number of enterprises employing 10-19 workers as well as the factor of the number of enterprises employing 20-49 workers show a positive sign, while the factor of the number of enterprises employing 1-9 workers shows a negative sign. Also, the p-value of independent variables indicates that these are statistically significant because for the first variable we have $\mathrm{p}$-value $=0.0135$ which is less than 0.05 (statistical significance level 95\%), for the second variable we have $p$-value $=0.0002$ which is less than 0.01 (statistical significance level) $99 \%$ ), for the third we have $\mathrm{p}$-value $=0.0007$ which is less than 0.01 (statistical significance level 99\%) and for the fourth we have $\mathrm{p}$-value $=0.0456$ which is less than 0.05 (statistical significance level 95\%). The modeling resulting from the Fixed Effects Model (Fixed Effects Model) is formulated as follows:

$\mathrm{EMP}=0,192835+0,020714 \mathrm{NBD}-0,003606 \mathrm{EMP} 1+0,036008 \mathrm{EMP} 2+0,013764 \mathrm{EMP} 3+\mathrm{U}_{\mathrm{it}}$ 
In conclusion, we can mention that in all the regressions that we carried out the independent variables that we used were statistically significant (at a materiality level of 90\%, 95\% and 99\%), which shows that the density of entry of new businesses into business activity (NBD), the number of enterprises employing 19-20 workers (EMP2) the number of enterprises employing 21-49 workers (EPM3) as well as the number of enterprises employing over 250 workers (EMP5) are positively related to the size of employment as a percentage of the total population (EMP), while the number of enterprises employing 1-9 workers (EMP1) is negatively related the size of employment as a percentage of the total population (PCR). The application of the DCRISIS in the regressions we have executed has helped us to reflect the impact of the financial crisis on employment in the EU member states. Its values are statistically significant and its impact is negative.

Although the degree of suitability of the models is not quite satisfactory, as R-Square does not exceed $50 \%$ of the variability of the data, the value Prob (F-Statistic) of each regression is statistically significant, thus making each model appropriate and giving us the opportunity to proceed with the interpretation Finally, in all cases, the Fixed Effects Model was considered more appropriate through the Hausman Test that we applied in each case, our predictions regarding their sign were confirmed and coincide with both economic theory and previous studies. 


\section{Conclusions}

So, we see that in today's competitive environment, entrepreneurship is a vital element of economic, social and personal success. It is not confined to creating a business, an innovative product or service, but is a complex process that takes place in a variety of areas of modern business and organizations. In today's times the concept of entrepreneurship is inextricably linked with the economy and the sizes that shape it, since we operate in an economic environment that is constantly differentiated and the survival and growth of the enterprises involved in it depends on many factors.

In the context of the analysis and development of the term entrepreneurship we conclude that as a definition and concept varies depending on the prism of its study, as in the global literature it is found from productive factor to integrated process and behavior.

In times of recession and economic crisis, the development of business activity, and especially youth entrepreneurship, can be the means of escape both to individuals and to the collective

level. The new entrepreneur has to make wise and realistic decisions in order to succeed because he operates in a business environment where there are two counterparts. On the one hand, the incentives offered, such as the Investment Law and the inclusion in the special status of "Youth Entrepreneurship" with the financing of business proposals, on the other hand, the disincentives, such as high taxation, bureaucracy and corruption, prevent it. A prerequisite is to have the appropriate tools to be able to plan and plan the course of its business.

The system of high taxation which does not support entrepreneurship and investment and is considered unfair by taxpayers is also characterized by the nonprofitability of taxes. In this climate, problematic tax rules create difficulties for entrepreneurship and can lead to unproductive forms of it (Komninos et.al, 2020a; Komninos et al., 2020b).

A further important conclusion can be drawn is the fact that unemployment is potentially driving the unemployed into business, as there is a positive correlation between these two factors. Through the research we conclude that working hours and 
the relationship between working hours and income are related to young entrepreneurs, while employment status, the search for and ultimately find business employment, the desire to change jobs and the existing prospects of economic growth are dependent on entrepreneurship early on. These conclusions are consistent with the results of previous surveys, which show that there is an unbreakable positive link between unemployment, entrepreneurship and new jobs.

In view of the above, unemployment is a key factor in entrepreneurship, which in turn helps to reduce unemployment and create job prospects, but there is a need to support the unemployed in investing in entrepreneurship and to encourage and support it through a proper institutional system

framework. This support refers to the creation of a comprehensive framework of support actions and services, which are essential to business development.

Overall, therefore, entrepreneurship, as analyzed through the literature review and primary research, is an essential factor in employment and can lead to economic growth. It is therefore necessary to give priority to entrepreneurial activity by creating a favorable framework for its development. 


\section{ETHICAL STATEMENT AND DATA AVAILAB ILITY}

a. Funding :

No funding was received.

b. Conflict of interest:

On behalf of all authors, the corresponding author states that there is no conflict of interest.

c. Ethical approval and d. informed consent:

The research carried out in this work was taken into account with respect to the observance of all the rules of ethics that govern the conduct of such research.

Acknowledgements:

None declared

Data availability:

Our manuscript contains data, which will be made available on reasonable request 


\section{References}

Acs, Z., J. (1992). 'Small Business Economic: A Global Perspective'. Challenge 35 (November-December).

Anastasiou A., Komninos D., Dermatis Z. and Marinopoulou E. (2021). 'Female Entrepreneurship and Economic Crisis in EU-28: The Case of Greece', International Journal of Economics and Business Research, DOI: 10.1504/JJEBR.2022.10038808.

Anastasiou A. and Panagiotopoulou E. (2020). 'The Strengthening of Economic Growth through the Contribution of Start-Up Entrepreneurship', The Hellenic Open Business Administration Journal, Vol. 7 (1), 73-87.

Audretsch, D., Thurik, R. (2004) A model of the entrepreneurial economy. International Journal of Entrepreneurship Education. 2(2): 143-166

Baumol, W., J. (1993). 'Formal Entrepreneurship Theory in Economics: Existence and Bounds". Journal of Business Venturing.

Dujowich, P. (2012) The dynamic relationship between entrepreneurship, unemployment and growth: Evidence for US industries.

Grebel E.K. (2000) In Star Formation from the Small to the Large Scale, 33rd ESLAB Symposium

Hayton and Zehra (2002). National Culture and Entrepreneurship: A review of Behavioral research

Hebert, R. F. and A. N. Link (1989). "In search of the Meaning of Entrepreneurship", Small Business Economy

Honig, B. Karlsson, T. (2004) Institutional forces and the written business plan.

Kakouris, A., Apostolopoulos, N., Dermatis, Z., Komninos, D., Liargovas, P. (2018). Entrepreneurial efficacy and orientation in Greece: exploring the gender gap. Int. J. Innovation and Regional Development, Vol. 8, No.3.

Komninos, D., Dermatis, Z., Anastasiou, A., Liargovas, P. (2020a). The effect of overtaxation and corruption at commercial enterprises in Greece: Evidence from a survey experiment. Journal of Statistical and Econometric Methods, Vol.9, No.4 
Komninos D., Dermatis Z., Anastasiou A. and Liargovas P. (2020b). 'The multiplicity and the frequent changes of the tax legislation in the Greek Tax Administration', Technium Social Sciences Journal, Vol. 13 (1), 395-407.

Lyroni, A., Anastasiou, A., Dermatis, Z., Komninos, D. (2018). Factors affecting the relationship between Research and Development $(R \& D)$ and economic development in EU. Advances in Economics and Business 6(5): 322-331

North, D., Thomas, R. (1973) The rise of the Western World: A New economic history. New York: Cambridge University Press.

Plehn-Dujowich Jose M.(2012). The Relation between CEO Compensation and Past Performance.

Romer, Paul, M. (1998). “Increasing Returns and Long Run Growth”. Journal of Political Economy.

Schultz, T., W. (1980). 'Investment and Entrepreneurial Ability'. Scandinavian Journal of Economics.

Wenneker, S. \& Thurik, R. (1999) Linking Entrepreneurship andEconomic Growth, Small Business Economics

Zervoyianni A. and Anastasiou A. (2009). 'Convergence of Shocks and Trade in the Enlarged European Union', Journal of International Trade and Economic Development, Vol. 18 (1), 79-114.

Zervoyianni A., Anastasiou A. and Anastasiou G.A. (2014). 'Does Central Bank Independence Really Matter? Re-Assessing the Role of the Independence of Monetary Policy-Makers in Macroeconomic Outcomes', International Journal of Economics and Business Research, Vol 8 (4), 427-473. 